\title{
NỘI SOI LỒNG NGỰC ĐIỀU TRI PHÃ̃ THUẠT U TRUNG THẤT TẠI BỆNH VIỆN TRUNG ƯƠNG QUÂN ĐỘI 108
}

\section{TS. Trần Trọng Kiểm*}

\section{TÓM TẮT}

Mở đầu: Nội soi lồng ngục điều trị phẫu thuật u trung thất ngày nay đã được áp dụng rộng rãi vì có nhiều ưu điểm hơn so với phưong pháp phẫu thuật truyền thống.

Mục tiêu: Đánh giá kết quả nội soi lồng ngụcc điều trị phẫu thuật u trung thất.

Phưong pháp nghiên cúu: Hồi cứu, tiến cứu mô tả bệnh chưng các truờng hơp u trung thất được phẫu thuật nội soi tại Bệnh viện 108 tù 1/2011 đến 6/2012

Kết quả: 36 bệnh nhân (20nam -16 nũu) được chẩn đoán u trung thất được phẫu thuật nội soi cắt u tại Bệnh viện 108. Tuổi trung bình là 45,67 $\pm 1,88$ (16-59 tuổi). Kích thuớc u 4,22 $\pm 0,24 \mathrm{~cm}$ (lón nhất $8 \mathrm{~cm}$, nhỏ nhất 2cm). Vị trí u: trung thất truớc: 17(47,2\%), trung thất giũa :10 (27,8\%), trung thất sau: 9 (25,0\%). Thờ gian phẫu thuật trung bình: $81,11 \pm 4,38$ phút (40 - 120 phút). Số ngày nằm điều trị trung bình 7,00 ngày. Không có tai biến, biến chứng trong và sau mổ.

Kết luận: Nội soi lồng ngục điều trị phẫu thuật u trung thất là một phuoong pháp an toàn, có tính thẩm mỹ cao, thời gian hậu phẫu ngắn, giảm biến chưng nhiềm khuẩn giúp bệnh nhân phuc hồi nhanh hon, trở lại với công việc sóm hơn so với mổ mỏ.

\section{ABSTRACT}

THORACOSCOPY IN THE SURGICAL MANAGEMENT OF MEDIASTINAL TUMOR IN 108 MILYTARY CENTRAL HOSPITAL

\section{TS. Trần Trọng Kiểm*}

Introduction: Nowadays, thoracoscopy in the surgical management of mediastinal tumor is adopted widely because of many advantages compared to traditional method.
Objectives: Evaluate result of thoracoscopy in the surgical management of mediastinal tumor.

Methods: Retrospective, prospective and descriptive study for all patients, who had mediastinal tumor and were operated with thoracoscopy in 108 hospital from 1/2011to 6/2012.

Results: 36 patients (20male-16female) who diagnosed medias tumor and were operated with

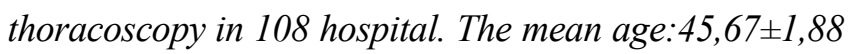
y.o (16-59 y.o). Tumor size: 4,22 $\pm 0,24 \mathrm{~cm}$ (maximum $8 \mathrm{~cm}$, minimum 2cm). Tumor position: anterior mediastinum 17(47,2\%), middle mediastinum 10(27,8\%), posterior mediastinum 9(25,0\%). Operating time: 81,11 4,38min (40-120 min). Postoperating time: 7,00 days. There aren't complications.

Conclusions: Thoracoscopy for mediastinal tumor resection is the safe and aesthetic procedure, what can be reduced postoperating time, infection, therefore, patients can be recovered and come back to work rapidly.

\section{ĐẠT VẤN ĐỀ}

Trung thất là một khoang chật hẹp của lồng ngực nhưng lại chứa nhiều cơ quan quan trọng như tim, mạch máu lớn, khí quản, thực quản... vì vậy các khối $\mathrm{u}$ trung thất dù lành tính hay ác tính đều có thể gây ra những rối loạn trầm trọng cho cơ thể.

Trước kia, điều trị ngoại khoa u trung thất rất nặng nề vì phải mở ngực và đôi khi phải bổ xương ức. Ngày nay, với sự phát triển của y học, nội soi lồng

* Bệnh viện trung uoong Quân đội 108

Người chịu trách nhiệm khoa học: TS Trần Trọng Kiểm Email:dr.trantrongkiemb4h108@gmail.com

Ngày nhận bài: 08/06/2013

Ngày Cho Phép Đăng: 13/6/2013

Phản Biện Khoa học: GS.TS. Đặng Ngoc Hùng GS.TS.Bùi Đức Phú 
ngực đã trở thành một phương tiện có nhiều ưu điểm trong chẩn đoán, điều trị các bệnh lý thuộc trung thất [3] [4] [7].

Khoa phẫu thuật lồng ngực - bệnh viện trung ương quân đội 108 đã ứng dụng phẫu thuật nội soi lồng ngực để điều trị một số $u$ trung thất đạt kết quả tốt

\section{ĐỐI TƯợNG PHƯƠNG PHÁP NGHIÊN CÚU}

\section{Đối tượng nghiên cứu}

Gồm 36 bệnh nhân có u trung thất được phẫu thuật nội soi lồng ngực tại Bệnh viện 108 từ tháng $1 / 2011$ đến $6 / 2012$.

\section{Phương pháp nghiên cứu}

Tiêu chuẩn lỵa chọn: các trường hợp có u trung thất được chẩn dựa trên các tiêu chuẩn sau:

- Có hình ảnh u trung thất X quang hoặc CT scanner lồng ngực.

- Trên CT scanner chưa có dấu hiệu xâm lấn các cơ quan quan trọng khác trong lồng ngực (tim, thực quản, khí quản...)

\section{Tiêu chuẩn loại trù:}

- Có các chống chỉ định tuyệt đối phẫu thuật: bệnh lý nội khoa nặng.

- Không thông khí chọn lọc được một bên phổi (đối bên tổn thương).

- Dày dính khoang màng phổi bên lựa chọn can thiệp.

\section{Chuẩn bị bệnh nhân}

Các bệnh nhân vào viện được hoàn thành các xét nghiệm chẩn đoán và xét nghiệm đánh giá toàn trạng.

Giải thích về bệnh lý và phương pháp điều trị.

\section{Qui trình phẫu thuật}

- Phương pháp vô cảm: mê nội khí quản 2 nòng.

- Tư thế bệnh nhân:

U trung thất trước, giữa: bệnh nhân nằm nghiêng về phía đối diện $45^{\circ}$.

U trung thất sau: bệnh nhân nằm nghiêng về phía đối diện $90^{\circ}$.

- Vị trí đặt và số Trocar sử dụng: thường sử dụng 3 trocar, một số ít trường hợp sử dụng 4 trocar.
Trocar camera thường đặt ở khoang gian sườn 4,5,6 đường nách giữa.

Hai (hoặc ba) trocar dụng cụ đặt dưới hướng dẫn của camera ở các vị trí thuận lợi cho kỹ thuật (thường đặt ở đường nách trước, đường giữa đòn)

Tùy theo vị trí u mà tiếp cận trung thất qua đường bên phải hoặc bên trái.

Dụng cụ nội soi của hãng Karl-Storz.

- Kỹ thuật mổ:

Kỹ thuật bóc tách, cắt bỏ khối u trung thất giống như mổ mở.

Khối u sau khi cắt bỏ được lấy ra qua lỗ trocar dụng cụ (có thể mở ngực tối thiểu để lấy khối u).

Kiểm tra cầm máu, đặt dẫn lưu dịch khoang màng phổi bên can thiệp qua lỗ trocar camera bằng sonde silicon $32 \mathrm{Fr}$. Kiểm tra phổi nở trước khi đóng ngực.

Bệnh phẩm được làm giải phẫu bệnh lý.

\section{Theo dõi hậu phẫu}

Chụp X-quang và siêu âm khoang màng phổi kiểm tra sau 24 giờ. Rút dẫn lưu khi đủ điều kiện.

Thu thập kết quả

Chụp X-quang và siêu âm kiểm tra trước ra viện.

\section{KẾT QUẢ}

Đặc điểm chung

Tuổi và giới:

\begin{tabular}{|l|c|c|}
\hline Đặc điểm & Sống 1: Tuổi vàọ̀ng giới & Tỷ lệ \% \\
\hline Nam & 20 & 55,6 \\
\hline Nữ & 16 & 44,4 \\
\hline Tổng & 36 & 100 \\
\hline Tuổi trung bình & \multicolumn{2}{|c|}{$45,67 \pm 1,88$ tuổi } \\
\hline
\end{tabular}

- Tuổi trung bình: 45,67士1,88 tuổi (16-59 tuổi).

Đạcc điểm tổn thương

- Vị trí tổn thương 
Bảng 2: Vị trí tổn thương

\begin{tabular}{|l|c|c|}
\hline Vị trí & Số lượng & Tỷ lệ \% \\
\hline Trung thất trước & 17 & 47,2 \\
\hline Trung thất giữa & 10 & 27,8 \\
\hline Trung thất sau & 09 & 25,0 \\
\hline Tổng & 36 & 100 \\
\hline
\end{tabular}

- Kích thước: 4,22 $\pm 0,24 \mathrm{~cm}$ (lớn nhất $8 \mathrm{~cm}$, nhỏ nhất $2 \mathrm{~cm}$ )

- Bản chất tổn thương

Bảng 3: Bản chất tổn thương

\begin{tabular}{|l|c|c|}
\hline Bản chất & Số lưọng & Tỷ lệ \% \\
\hline Hạch lao & 02 & 5,6 \\
\hline Nang thanh dịch & 03 & 8,3 \\
\hline U lympho & 02 & 5,6 \\
\hline Sarcoidose & 05 & 13,9 \\
\hline U tuyến ức & 15 & 41,7 \\
\hline U thần kinh & 09 & 24,9 \\
\hline Tổng & 36 & 100 \\
\hline
\end{tabular}

\section{Kết quả phẫu thuật}

Thời gian phẫu thuật: $81,11 \pm 4,38$ phút (40-120 phút)

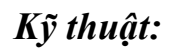

Bảng 4: Các yếu tố kỹ thuật

\begin{tabular}{|l|l|c|c|}
\hline \multicolumn{2}{|l|}{ Kỹ thuật } & Số lượng & Tỷ lệ \% \\
\hline \multirow{2}{*}{ Tư thế } & Nghiêng 45 & 27 & 74,3 \\
\cline { 2 - 4 } & Nghiêng 90 & 09 & 25,7 \\
\hline \multirow{2}{*}{ Đường vào } & Bên phải & 20 & 55,6 \\
\cline { 2 - 4 } & Bên trái & 16 & 44,4 \\
\hline \multirow{2}{*}{$\begin{array}{l}\text { Số trocar } \\
\text { sử dụng }\end{array}$} & 3 trocar & 34 & 94,4 \\
\cline { 2 - 4 } & 4 trocar & 02 & 5,6 \\
\hline
\end{tabular}

\section{Biến chứng trong và sau mổ}

Không có biến chứng trong và sau mổ.

\section{Thời gian rút dẫn lưu}

Các dẫn lưu được rút sau 1 - 3 ngày. Trung bình là 2 ngày.

\section{Thời gian nằm viện}

Thời gian nằm viện trung bình từ sau khi can thiệp là 7,00 ngày ( 5 - 11 ngày).

\section{BÀN LUẬN}

Về đặc điểm chung: $u$ trung thất có thể gặp ở mọi lứa tuổi và nhiều hình thái tổn thương khác nhau. $\mathrm{U}$ tuyến ức chiếm đa số (15 trường hợp chiếm 41,7\%), u thần kinh đứng hàng thứ hai với $24,9 \%$, các u khác như sarcoidose, nang thanh dịch... chiếm tỷ lệ thấp ( khoảng từ $5-15 \%)$. Tỷ lệ này tương đồng với các nghiên cứu của Bradley, Decamp và cộng sự [2][3].

\section{Về chỉ định phẫu thuật}

Theo quan điểm của một số tác giả: phẫu thuật nội soi lồng ngực có thể áp dụng cho u trung thất lành tính hoặc ác tính giai đoạn sớm với kích thước dưới $8 \mathrm{~cm}$, tuy nhiên cũng có tác giả đã thông báo những trường hợp nội soi u trung thất với kích thước khối u lớn nhất $10 \mathrm{~cm}[5][7]$.

Trong nghiên cứu này, chúng tôi gặp phần lớn $\mathrm{u}$ trung thất lành tính, chỉ có 2 trường hợp ác tính đều là $\mathrm{u}$ lympho. $\mathrm{U}$ trung thất trước hay gặp nhất $(47,2 \%)$. Kích thước u lớn nhất là $8 \mathrm{~cm}$. Với các trường hợp được nghiên cứu chúng tôi thấy kích thước $\mathrm{u}$ không ảnh hưởng đến kỹ thuật, các khó khăn trong phẫu thuật thường gặp do $\mathrm{u}$ dính vào các cơ quan xung quanh, phổi xẹp không hoàn toàn trong quá trình phẫu thuật

Như vậy, có thể chỉ định ứng dụng nội soi lồng ngực trong can thiệp các $u$ trung thất lành tính và ác tính với kích thước khối $\mathrm{u}<8 \mathrm{~cm}$, chưa xâm lấn vào các cơ quan xung quanh. 


\section{Về kỹ thuật}

+ Phương pháp vô cảm: Chúng tôi sử dụng gây mê nội khí quản 2 nòng cho tất cả các trường hợp được nghiên cứu. Việc thông khí chọn lọc một bên phổi sẽ giúp cho phổi bên cần can thiệp xẹp lại tạo phẫu trường rộng rãi thuận lợi cho tiến hành kỹ thuật. Đây cũng là một yếu tố quan trọng giúp hạn chế các biến chứng trong mổ [1].

+ Tư thế bệnh nhân: Chúng tôi sử dụng 2 tư thế nghiêng $45^{\circ}$ và nghiêng $90^{\circ}$ tùy thuộc vào vị trí của khối u ở trung thất trước, giữa hay sau. Có rất nhiều quan điểm về tư thế phẫu thuật. Mai Văn Viện cho rằng tư thế ngửa- nghiêng $30^{\circ}$ và sấp - nghiêng $30^{\circ}$ là hai tư thế thuận lợi nhất để tiến hành kỹ thuật và kiểm soát biến chứng. Văn Tần, Yim. A thường sử dụng tư thế nghiêng $90^{\circ}$ [5] [7] [8].

+ Số trocar và đường vào trung thất: Chưa có tài liệu chính thống nào quy định về số trocar và đường vào trung thất trong phẫu thuật nội soi u trung thất. Tuy nhiên, đa số các tác giả đều nhận thấy thông thường chỉ cần 3 trocar là đủ, đường vào trung thất phụ thuộc vào vị trí của khối u lệch về bên nào sẽ vào qua đường bên đó để tiếp xúc tổn thương trực tiếp hơn [4][5][6]. Kết quả của chúng tôi phù hợp với nhận xét chung đó: 94,4\% (34/36) trường hợp sử dụng 3 trocars, 5,6\% (2/36) trường hợp sử dụng 4 trocar đây là 2 trường hợp phổi bên can thiệp không xẹp hoàn toàn gây cản trở quá trính phẫu thuật, chúng tôi phải đặt thêm 1 trocar để đưa dụng cụ vào đè, vén phổi bổ xung, không liên quan đến yếu tố tổn thương.Việc lựa chọn đường vào qua khoang màng phổi phải hay trái phụ thuộc vị trí của khối u. Mặc dù chúng tôi sử dụng đường vào bên phải nhiều hơn bên trái $(55,6 \%$ so với $44,4 \%)$ nhưng sự khác biệt này không có ý nghĩa thống kê.

\section{Kết quả điều trị}

+ Thời gian phẫu thuật trung bình $81,11 \pm 4,38$ phút, dẫn lưu thường được rút sau mổ 2 ngày khi đã được chụp $X$ quang và siêu âm khoang màng phổi kiểm tra, bệnh nhân ra viện sau 7,00 ngày. Kết quả của chúng tôi đưa ra tương đương với kết quả trong nghiên cứu của Mai Văn Viện, Văn Tần [5][8].

So với mổ mở, phẫu thuật nội soi làm giảm rõ rệt thời gian hậu phẫu và thời gian nằm viện. Đối với mổ mở, việc mở ngực, banh xương sườn hoặc bổ xương ức trong quá trình phẫu thuật gây ảnh hường rất lớn đến sự hồi phục của bệnh nhân. Sau mổ bệnh nhân thường đau nhiều làm hạn chế cử động thở kết hợp vết mổ lớn, nguy cơ đọng dịch, nhiễm khuẩn vết mổ cao làm kéo dài thời gian hậu phẫu và thời gian nằm viện (thường hơn 10 ngày).

+ Tai biến, biến chứng: Chúng tôi không gặp tai biến, biến chứng trong và sau mổ. Có lẽ là do số bệnh nhân nghiên cứu còn ít, các trường hợp nặng, khó chưa nhiều. Trong một số nghiên cứu khác, tác giả thường gặp các tai biến, biến chứng như chảy máu trong mổ, suy hô hấp [5][6].

\section{KẾT LUẬN}

Qua 36 trường hợp u trung thất được phẫu thuật nội soi lồng ngực tại Bệnh viện Trung ương quân đội 108 từ 1/2011 đến 6/2012 chúng tôi nhận thấy: Phẫu thuật nội soi điều trị u trung thất là phẫu thuật an toàn, có tính thẩm mỹ cao, thời gian hậu phẫu ngắn, giảm biến chứng nhiễm khuẩn giúp bệnh nhân phục hồi nhanh hơn, trở lại với công việc sớm hơn so với mổ mở.

\section{TÀI LIỆU THAM KHẢO}

1. Ali Mahtabifard, Robert J. McKenna Jr. (2009), "Video-Assisted Thoracic Surgery for Wedge Resection, Lobectomy, and Pneumonectomy", General Thoracic Surgery, 7th Edition, Lippincott Williams \& Wilkins, USA, pp. 527.

2. Bradley S.P (1996), "Mediastinal mass", Manual of Clinical Problems in Pulmonary Medicine 4 th Ed. Ed. by R.A. Bordow and K.M. Moser, A Little, Brown \& Co.USA, pp. 482-486. 
3. Decamp M.M; Swanson S.J; Sugarbaker D.J (1996), "Mediastinum", Glenn's Thor. and Cardiovasc. Surg. 6th, Appleton and Lange, USA, pp. 643-664.

4. Alberto de Hoyos (2009), "Video-Assisted Thoracic Surgery for Diseases Within the Mediastinum", General Thoracic Surgery, 7th Edition, Lippincott Williams \& Wilkins, USA, pp. 2158-2173.

5. Mai Văn Viện (2010), "Ứng dụng phẫu thuật nội soi lồng ngực điều trị u trung thất tại Bệnh viện 103", Y học thành phố Hồ Chí Minh, 14(3), tr. 529-535
6. Nguyễn Hoài Nam (2003), "Những cải tiến kỹ thuật trong phẫu thuật nội soi lồng ngực", Ngoại khoa, 6, tr. 12- 23

7. Văn Tần, Hoàng Danh Tấn, Trần Công Quyền, Hồ Nam, Hồ Huỳnh Long, Nguyễn Ngọc Bình (2010), " Phẫu thuật bướu trung thất qua nội soi lồng ngực”, Y học thành phố Hồ Chí Minh, 14(4), tr. 552-558.

8. Yim APC (1996), "VATs resection of anterior mediastinal masses", Int J Surg, 81, pp. 350.1996 